\title{
IMPACT OF OUTDOOR LIGHTING ON MOTHS
}

\author{
KENNETH D. FRANK
}

Philadelphia, PA U.S.A.

\begin{abstract}
Outdoor lighting incapacitates and destroys some moths. It disturbs flight, navigation, vision, migration, dispersal, oviposition, mating, feeding, and crypsis. It may also shift circadian rhythms. Lamps may incinerate or desiccate moths, or lead to moth's destruction by birds, bats, spider, and vehicular traffic. Conservation efforts need to consider disruptive ecological effects of outdoor lighting. Low pressure sodium lamps may reduce these effects.
\end{abstract}

